\title{
Epigenetic silencing of XAF1 in high-grade gliomas is associated with IDH1 status and improved clinical outcome
}

\author{
Thomas R. Reich ${ }^{1}$, Olivier J. Switzeny ${ }^{1}$, Mirjam Renovanz ${ }^{2}$, Clemens Sommer $^{3}$, \\ Bernd Kaina ${ }^{1}$, Markus Christmann ${ }^{1}$, Maja T. Tomicic ${ }^{1}$ \\ ${ }^{1}$ Department of Toxicology, University Medical Center, D-55131 Mainz, Germany \\ ${ }^{2}$ Department of Neurosurgery, University Medical Center, D-55131 Mainz, Germany \\ ${ }^{3}$ Department of Neuropathology, University Medical Center, D-55131 Mainz, Germany \\ Correspondence to: Maja T. Tomicic, email: tomicic@uni-mainz.de \\ Markus Christmann, email: mchristm@uni-mainz.de
}

Keywords: high-grade glioma, glioblastoma, temozolomide, XAF1 promoter methylation, IDH1

Received: July 22, 2016

Accepted: January 10, 2017

Published: January 19, 2017

\section{ABSTRACT}

XAF1 (X-linked inhibitor of apoptosis (XIAP)-associated factor 1 ) is a tumor suppressor that counteracts the anti-apoptotic effects of XIAP and can sensitize cells to cell death triggering events. XAF1 knockdown abrogated the temozolomide (TMZ)induced G2-arrest and prevented TMZ-induced apoptosis in the glioblastoma (GB) cell line LN229. Promoter methylation of XAF1 was found to be inversely correlated with mRNA expression in GB cells. We analyzed XAF1 methylation in a panel of $16 \mathrm{~GB}$ cell lines and 80 patients with first-diagnosed WHO grade III/IV high-grade gliomas using methylation-sensitive high-resolution melt (MS-HRM) analysis. In those patients, $X A F 1$ promoter methylation was strongly associated with enhanced progression free and overall survival. Interestingly, XAF1 promoter methylation was strictly correlated with the occurrence of IDH1 mutations, indicating a causal link to the IDH1 mutant phenotype. XAF1 methylation was observed in 18 grade III tumors all of which showed heterozygous mutations in the IDH1 gene. 17 harbored a mutation leading to an arginine $>$ histidine $(\mathrm{R} 132 \mathrm{H})$ and one carried a mutation causing an arginine $>$ glycine (R132G) substitution. Furthermore, six out of six recurrent and IDH1 mutated grade III tumors also showed XAF1 promoter methylation. The data demonstrate that XAF1 promoter methylation determined by MS-HRM is a robust and precise indicator of IDH1 mutations in grade III gliomas. It is useful for complementing the immunohistochemistry-based detection of mutant IDH, uncovering rare 2-HGproducing IDH1 and potentially IDH2 mutations. The MS-HRM-based detection of $X A F 1$ methylation could therefore be a reliable tool in assisting the sub-classification of high-grade gliomas.

\section{INTRODUCTION}

In accordance with the 2007 World Health Organization (WHO) guidelines [1], tumors of the central nervous system have been classified by histological criteria. This not only defines the tumor type, but also the grade of malignancy. High-grade gliomas (HGG) or malignant gliomas mainly consist of WHO grade III and grade IV tumors. Glioblastomas (GB) (WHO grade IV) account for $60-70 \%$ of HGG. Among WHO grade III tumors anaplastic astrocytomas (AA) account for 10-15\% and anaplastic oligodendrogliomas (AO) together with anaplastic oligoastrocytomas (AOA) for 10\% of HGG [2]. Due to massive progress in the knowledge of the genetic basis of tumorigenesis, a major revision of the HGG classification was necessary as suggested by the Haarlem consensus guidelines for nervous system tumor classification and grading [3], which finally culminated in the 2016 update of the WHO guidelines [4]. In the new classification, histology and molecular parameters are used to define the different tumor entities. The 2016 WHO classification is mainly based on three molecular markers: isocitrate dehydrogenase 1/2 (IDH1/IDH2) mutations, allelic loss of chromosome $1 \mathrm{p}$ and $19 \mathrm{q}$, as well as somatic mutations 
in the alpha thalassemia/mental retardation syndrome $\mathrm{X}$-linked (ATRX) gene.

Of utmost importance for molecular classification and prognosis in gliomas is the status of the IDHI gene. Specific mutations in this gene are associated with a strongly improved clinical outcome [5, 6]. IDH1 mutations are found in more than $70 \%$ of WHO grade II/ III astrocytomas and oligodendrogliomas as well as in secondary GB [6], therefore linking $I D H 1$ mutation predominantly to lower grade and grade III gliomas, as well as GB having evolved from the aforementioned. The most common mutation found in $\mathrm{IDH} 1$ leads to an arginine to histidine substitution $(\mathrm{R} 132 \mathrm{H})$ in the active site of the protein [7]. As gain-offunction mutation, this enables the enzyme to produce 2-hydroxyglutarate (2-HG) instead of its normal product $\alpha$-ketoglutarate $(\alpha \mathrm{KG})$ [8]. This oncometabolite is sufficient to establish the glioma $\mathrm{CpG}$ island methylator phenotype (G-CIMP) [9] that is associated with distinct molecular subgroups of gliomas, linked to younger age at diagnosis and better prognosis [10]. The CIMP is characterized by an extensive, coordinated hypermethylation at specific gene loci. Also, additional mutations in the $I D H 2$ gene, apart from IDH2 R172 (e.g. R140), which in gliomas occur less frequently than those in the IDH1 gene, give the same phenotype $[6,11-13]$.

The current treatment of $\mathrm{HGG}$ consists of a maximum safe resection followed by radiotherapy with concomitant or adjuvant temozolomide (TMZ) administration [14]. TMZ exerts its cytotoxic effect by the induction of $\mathrm{O}^{6}$-methylguanine, which, in the presence of the mismatch repair, ultimately leads to the formation of DNA double-strand breaks (DSB) and cell death [15]. $\mathrm{O}^{6}$-methylguanine can be repaired by the DNA repair enzyme $\mathrm{O}^{6}$-methylguanine-DNA methyltransferase (MGMT). Since MGMT expression is inhibited by methylation of its promoter, and $M G M T$ promoter methylation correlates with enhanced overall survival (OS) and progression free survival (PFS), the methylation status of $M G M T$ is used as a predictive marker for glioma therapy [16]. Previously, we observed that members of the inhibitor of apoptosis (IAP) family, Survivin and XIAP, can also protect malignant glioma cells from anticancer therapy [17]. An important factor, blocking the anti-apoptotic effect of Survivin and XIAP by targeting the proteins for proteasomal degradation, is the tumor suppressor $\mathrm{X}$-linked inhibitor of apoptosis (XIAP)-associated factor 1 (XAF1) [18, 19]. XAF1 is ubiquitously expressed in normal tissue, while in cancer cells its expression is often reduced [20]. XAF1 expression is absent or reduced in gastric [21], colon [21], ovarian [22], pancreatic [23], esophageal [24], hepatic [25], melanoma [26], and urogenital tumors [27-29], and is largely regulated by promoter $\mathrm{CpG}$ dinucleotide hypermethylation, which leads to gene silencing $[21,24,29]$. XAF1 protein expression was shown to suppress tumor cell growth and enhance cellular response to various apoptotic stimuli, such as 5-fluorouracil, etoposide, $\mathrm{H}_{2} \mathrm{O}_{2}, \gamma$-irradiation, UV light and $\mathrm{TNF} \alpha$, whereas knockdown of its expression protected cells from the stressors [30]. Furthermore, enhanced XAF1 expression inhibited cell proliferation and induced apoptosis in HCC cells [31] and in gastric and colon cancer xenografts $[32,33]$. In gastric cells, this seems to be associated with a role of XAF1 in inducing G2/M arrest [33]. This cell cycle arrest is explained by a direct interaction with the activated checkpoint kinase 1 (CHK1), leading to inactivation of $\mathrm{Cdc} 25 \mathrm{C}$ in the $\mathrm{Cdc} 2$-cyclin $\mathrm{B}$ complex [34]. Although there are no reports describing a direct impact of $X A F 1$ methylation on radiation sensitivity, there are few hints indicating that an increased XAF1 expression sensitizes cells towards ionizing radiation (IR). An association was found between a high expression of XAF1 and induction of apoptosis based on an ubiquitindependent degradation of CHK1 by the XAF1-XIAP complex, leading to enhanced radiation sensitivity [35].

The main goal of the present study was to elucidate whether $X A F 1$ is epigenetically silenced in HGG and whether the methylation status of the $X A F 1$ promoter can serve as a prognostic and/or predictive marker. Therefore, we utilized methylation-sensitive high-resolution melt (MS-HRM) analysis [36] that was recently shown to provide excellent prognostic outcomes in $M G M T$ promoter methylation studies [37]. By adopting this method, we analyzed the $\mathrm{CpG}$ methylation in a distinct promoter region of XAF1 in HGG cell lines and in 80 formalinfixed, paraffin-embedded (FFPE) tumor samples. These samples were obtained from HGG patients, prior to the standard IR/TMZ therapy. Additionally, 16 samples of recurrent HGG were analyzed.

\section{RESULTS}

\section{Influence of XAF1 knockdown on the response to TMZ}

To analyze a putative impact of XAF1 on TMZinduced cell death and/or cell cycle progression, XAF1 expression was silenced by siRNA in the GB cell line LN229. The effect of XAF1 knockdown on induction of apoptotic cell death (Figure 1) and cell cycle distribution (Figure 2) upon exposure to TMZ was determined. Measurement of the SubG1 fraction indicated that XAF1 knockdown protects in vitro against TMZ-induced apoptosis (Figure 1A). The data were confirmed by annexin V/PI double staining (Figure 1B), showing specific reduction of TMZ-induced apoptosis in XAF1-si transfected LN229 cells. Necrosis was only marginally induced ( $<5 \%$; data not shown). Furthermore, XAF1si transfected LN229 cells had a higher metabolic competence upon exposure to TMZ than the con-si transfected cells (Figure 1C). These in vitro data are in accordance with other reports, demonstrating that 
enhanced XAF1 expression induces apoptosis in tumor cells [31] and in xenografts [32, 33].

In comparison to short-term exposure (subG1, annexin V, MTT), there was no difference in colony formation (reproductive cell survival) between XAF1-si and con-si transfected TMZ-exposed LN229 cells (Figure 1D). This indicates that for long-term survival differences, the impact of XAF1 on cellular processes beside apoptosis, for instance on cell cycle progression, plays a predominant role. Thus, we observed that upon $X A F 1$ knockdown, LN229 cells exposed to TMZ did not accumulate in the G2phase. The cells rather accumulated in the G1-phase (72-96 h) and later-on (120 h upon TMZ exposure) in the S- and G2-phase (Figure 2A).

Furthermore, the expression of XAF1, XIAP, and Survivin, as well as the activation of CHK1 (which is important for TMZ-induced G2-arrest) was analyzed upon TMZ treatment depending on $X A F 1$ silencing (Figure 2B). The data show that $X A F 1$ knockdown led to the stabilization of Survivin, as compared to the con-si transfected TMZ-exposed cells, and also protected from down-regulation (degradation) of XIAP. Importantly, activation (phosphorylation) of CHK1 (pCHK1) was reduced upon $X A F 1$ knockdown.

Since the in vitro data in GB cells suggest an impact of XAF1 on the sensitivity to TMZ, we addressed the question whether XAF1 expression plays a role in the course of disease of malignant gliomas.

\section{XAF1 promoter methylation is predictive for XAF1 expression}

To analyze whether XAF1 expression represents a prognostic marker in HGGs, we established a MS-HRM
A

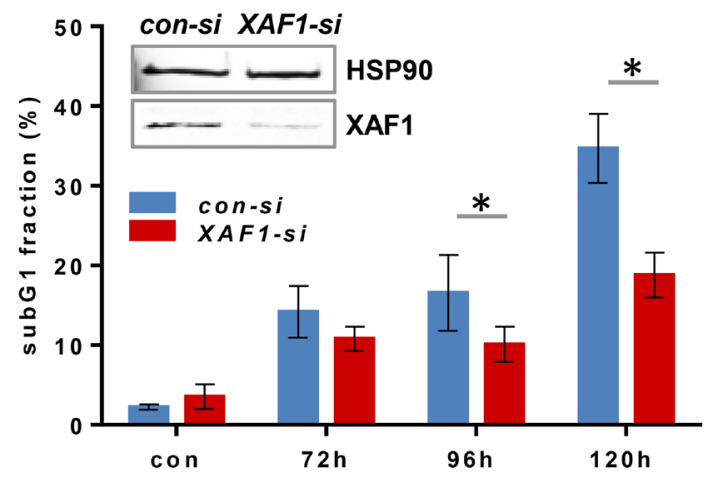

C

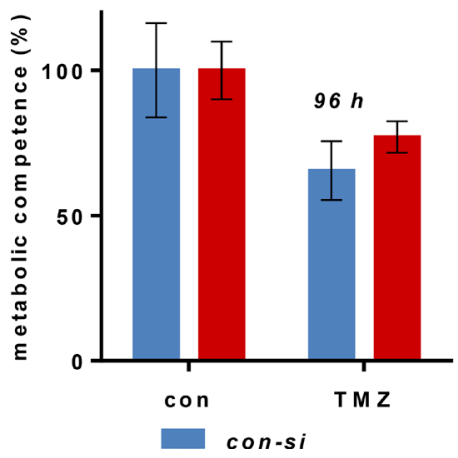

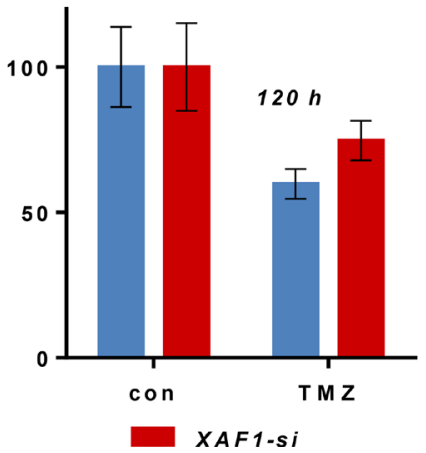
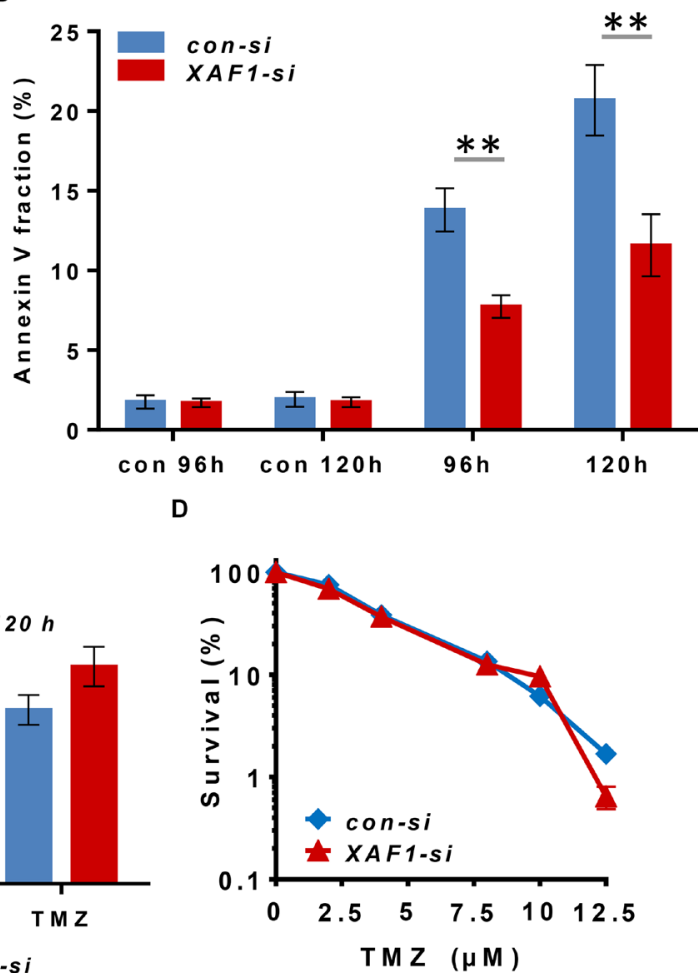

Figure 1: Cytotoxicity end points upon siRNA-mediated $X A F 1$ silencing in malignant glioma cells exposed to TMZ. $X A F 1$ knockdown was performed $24 \mathrm{~h}$ prior to the treatment of the cells. Time points indicated refer to the treatment time (A) Flow cytometric analysis of apoptosis induction (subG1) is shown in LN229 cells after XAF1 knockdown (XAF1-si) and transfection with noncoding siRNA (con-si). Cells were treated with $100 \mu \mathrm{M} \mathrm{TMZ}$ and fixed after the time points indicated. After PI staining, the subG1 fraction was determined. Error bars indicate the SD in three independent experiments in duplicates $(N=3)$. Data were analyzed for statistically significant differences by two-tailed $t$-test, comparing target XAF1-si vs. con-si. A $p$-value of $<0.05$ was considered to be statistically significant (*). The efficiency of siRNA-mediated XAF1 knockdown was verified by western blot analysis $24 \mathrm{~h}$ after transfection. HSP90 was used as loading control. (B) Flow cytometric analysis of annexin V-FITC/PI - stained LN229 cells upon transfection with con-si and $X A F 1$-si RNA and exposure to $100 \mu \mathrm{M} \mathrm{TMZ}$ for 96 and $120 \mathrm{~h}$. The corresponding unexposed controls (con $96 \mathrm{~h}$, con $120 \mathrm{~h}$ ) are shown. Error bars indicate the SD in two independent experiments in duplicates $(N=2)$. Data were analyzed for statistically significant differences by two-tailed $t$-test, comparing target $X A F 1$-si vs. con-si. A $p$-value of $<0.01$ was considered to be statistically significant (**). (C) The cell viability (metabolic competence) upon treatment with $100 \mu \mathrm{M} \mathrm{TMZ}$ was determined by MTT assay in con-si and XAF1-si transfected LN229 cells. Technical triplicates at 96 and $120 \mathrm{~h}$ are shown. (D) Colony forming assay of LN229 cells transfected with con-si and XAF1si RNA, exposed to increasing TMZ concentrations (semi-logarithmic scale). Two experiments in duplicates are shown. The unexposed controls were set to $100 \%$. 
assay for the detection of $X A F 1$ promoter methylation, using bisulfate-converted methylated and non-methylated genomic DNA. The primer pair used flanks three CpGs in the region -196 to -235 (Figure $3 \mathrm{~A}$ ), which overlaps with a region already found to be responsible for $X A F 1$ silencing in gastric cancer. MS-HRM was used for the methylation analysis of the selected $X A F 1$ promoter region in $16 \mathrm{HGG}$ cell lines (Figure 3B). Six cell lines showed an overall high methylation level (79-100\%). Four cell lines showed an intermediate methylation (34-78\%), whereas five cell lines showed a low methylation $(<33 \%)$.

To examine the methylation status of these CpGs in more detail, the region amplified by MSHRM was analyzed by pyrosequencing in six cell lines (Supplementary Table 1, Supplementary Figure 1). Methylation levels detected by pyrosequencing and MSHRM showed a strong correlation $(r=0.965 ; p=0.0018)$, verifying MS-HRM as accurate method for methylation analysis. Detailed methylation levels for all three CpGs analyzed are provided in Supplementary Table 1.

In order to identify a cut-off level, the promoter methylation of the cell lines was compared to the corresponding $X A F 1$ mRNA expression in 16 HGG cell lines (Figure 3C). XAF1 mRNA was only detectable for methylation levels of $\leq 33 \%$. LN229 cells exhibited an average methylation of $34 \%$ with almost non-detectable mRNA expression. Thereby using $33 \%$ as threshold for methylation, we were able to define cell lines as XAF1-methylated (XAF1-M) and XAF1-unmethylated (XAF1-UM). Applying this threshold to the glioma cell line panel, a significantly higher $X A F 1 \mathrm{mRNA}$ expression was found in the unmethylated group (Figure 3D, $p<0.0001$ ).

In addition to the mRNA expression, also XAF1 protein levels were determined in selected cell lines. In line with the previous findings, cell lines with no or low promoter methylation (LN319, U118, T98G, GBP61) showed expression of the XAF1 protein. In contrast, cell lines with a highly methylated $X A F 1$ promoter (U251, LN308) showed no detectable expression (Figure 3E). The situation is less clear for the cell lines showing an intermediate methylation level (e.g. LN229); in this case, expression of the protein was still evident. Since we observed the best stratification between $X A F 1$ mRNA expressing and $X A F 1 \mathrm{mRNA}$ non-expressing cell lines, using a cut-off level of $£ 33 \%$, we used this value for the analysis of the impact of $X A F 1$ methylation on clinical parameters in $\mathrm{HGG}$ patients.

\section{XAF1 promoter methylation in malignant brain tumors}

Having confirmed the biological relevance of the methylation in the three CpGs analyzed, for $X A F 1$ mRNA and protein expression, we evaluated the $X A F 1$ status in $80 \mathrm{HGG}$ tumor samples. A total of 26 patients $(32.5 \%)$ showed a methylated $X A F 1$ promoter in the tumor tissue analyzed with no gender prevalence (Table 1). XAF1 methylation occurred more often in patients with an age below 70 years at diagnosis. To test the influence of the $X A F 1$ methylation on the PFS and OS,
A
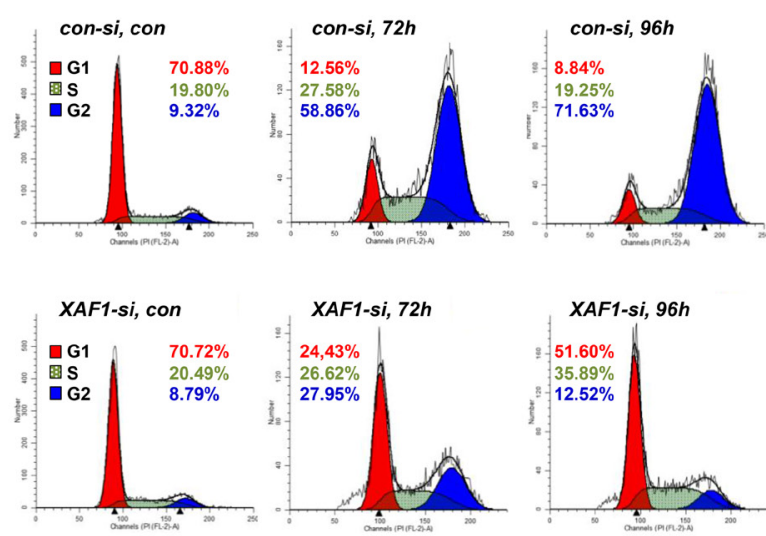
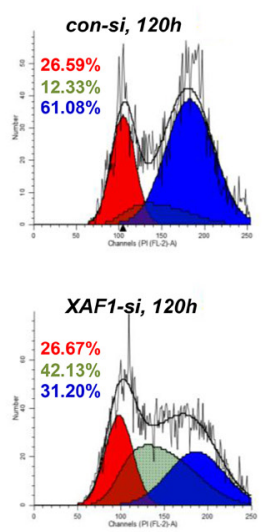
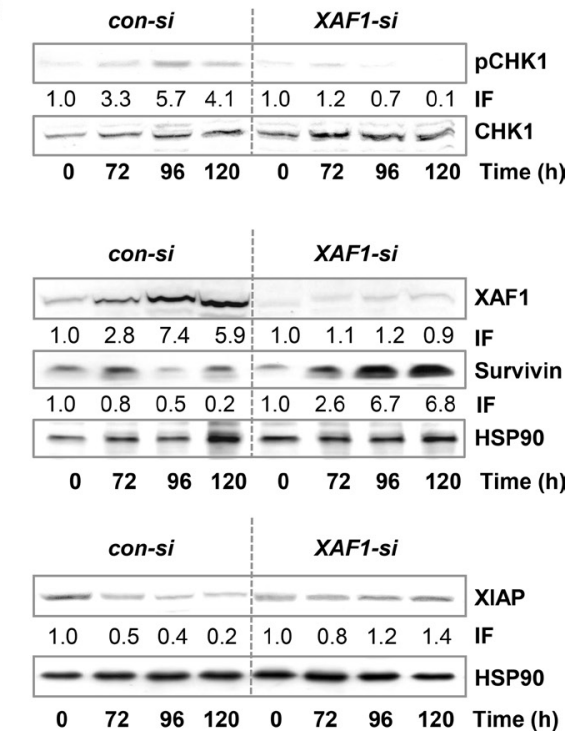

Figure 2: Cell cycle distribution and protein expression upon $X \boldsymbol{A F 1}$ knockdown. (A) The cell cycle distribution upon $X A F 1$ knockdown and transfection with con-si, was analyzed in a time frame of 72-120 hafter exposure to $100 \mu \mathrm{M}$ TMZ. Automated cell cycle analysis was performed using ModFit LT 3.3. The representative histograms of one out of three experiments are shown. (B) Protein levels of XAF1, XIAP, Survivin and phosphorylated CHK1 (pCHK1) with HSP90 as loading control, were determined upon TMZ treatment $(100 \mu \mathrm{M})$ and compared in XAF1-si and con-si transfected LN229 cells by western blot analysis. One representative blot out of three independent experiments is shown. The corresponding protein expression was quantified by densitometric analysis in relation to the loading control. IF = induction factor. 
Table 1: Patient's characteristics

\begin{tabular}{lccc}
\hline Characteristics & N & XAF1-M \% (N) & IDH1 mut \% (N) \\
\hline All patients & 80 & $32.5(26)$ & $25.0(20)$ \\
Women & 24 & $29.2(7)$ & $25.0(6)$ \\
Men & 56 & $33.9(19)$ & $25.0(14)$ \\
Age $<70$ & 56 & $41.1(23)$ & $35.7(20)$ \\
Age $\geq 70$ & 24 & $12.5(3)$ & $0.0(0)$ \\
Grade III* & 26 & $69.2(18)$ & $69.2(18)$ \\
Grade IV* & 54 & $14.8(8)$ & $3.7(2)$ \\
AA, AOA, AO IDHImut & 18 & $100.0(18)$ & $100.0(18)$ \\
AA, AOA, AO IDH/wt & 8 & $0.0(0)$ & $0.0(0)$ \\
GB IDH1mut & 2 & $100.0(2)$ & $100.0(2)$ \\
GB IDH1wt & 54 & $11.1(6)$ & $0.0(0)$ \\
\hline
\end{tabular}

$X A F 1$ promoter methylation $(X A F 1-\mathrm{M})$ was determined by MS-HRM and $I D H 1$ mutation.

(IDHImut) by pyrosequencing and IHC. *Histological tumor grade: AA: anaplastic astrocytoma;

AO: anaplastic oligodendroglioma; AOA: anaplastic oligoastrocytoma; GB: glioblastoma.

Table 2: Kaplan-Meier survival estimates for HGG patients

\begin{tabular}{lcccccccccc}
\hline PFS & \multicolumn{2}{c}{ all } & \multicolumn{2}{c}{ grade III* } & \multicolumn{2}{c}{ grade IV* } & \multicolumn{2}{c}{$\begin{array}{c}\text { AA, AOA, AO } \\
\text { IDH1mut }\end{array}$} & \multicolumn{2}{c}{$\begin{array}{c}\text { AA, AOA, AO } \\
\text { IDH1wt }\end{array}$} \\
\hline XAF1 & mean & median & mean & median & mean & median & mean & median & mean & median \\
\hline $\mathrm{UM}$ & 8.7 & 4.4 & 13.3 & 6.6 & 7.8 & 4.1 & - & - & 10.2 & 4.6 \\
M & 32.7 & 41.0 & 42.0 & 43.0 & 11.0 & 5.0 & 44.7 & n.d & - & - \\
p & 0.000 & \multicolumn{2}{c}{0.000} & \multicolumn{2}{c}{0.348} & & n.d. & n.d. \\
\hline
\end{tabular}

*Histological tumor grade. (n.d.: as survival in the particular group did not drop below 50\%). n.d., not determined.

\begin{tabular}{|c|c|c|c|c|c|c|c|c|c|c|}
\hline \multirow{2}{*}{$\begin{array}{l}O S \\
X A F 1\end{array}$} & \multicolumn{2}{|c|}{ all } & \multicolumn{2}{|c|}{ grade III* } & \multicolumn{2}{|c|}{ grade IV* } & \multicolumn{2}{|c|}{$\begin{array}{c}\text { AA, AOA, AO } \\
\text { IDH1mut }\end{array}$} & \multicolumn{2}{|c|}{$\begin{array}{c}\mathrm{AA}, \mathrm{AOA}, \mathrm{AO} \\
I D H 1 \mathrm{wt}\end{array}$} \\
\hline & mean & median & mean & median & mean & median & mean & median & mean & median \\
\hline UM & 16.8 & 12.0 & 21.9 & 19.0 & 15.3 & 11.0 & - & - & 16.4 & 11.0 \\
\hline M & 40.2 & n.d. & 49.8 & n.d. & 20.6 & 16.0 & 54.2 & n.d & - & - \\
\hline $\mathrm{p}$ & \multicolumn{2}{|c|}{0.000} & \multicolumn{2}{|c|}{0.000} & \multicolumn{2}{|c|}{0.196} & \multicolumn{2}{|c|}{ n.d. } & \multicolumn{2}{|c|}{ n.d. } \\
\hline
\end{tabular}

*Histological tumor grade. (n.d.: as survival in the particular group did not drop below 50\%). n.d., not determined.

Mean and median survival estimates according to the XAF1 methylation status for PFS and OS in different subgroups of the patients, collectively analyzed. $P$-values indicate the statistical significance of the differences in both groups (log-rank test).

promoter methylation status was used for stratification in Kaplan-Meier survival curves (Figure 4). Patients were dichotomized according to the defined threshold, as either $X A F 1-\mathrm{M}$ or $X A F 1-\mathrm{UM}$. Strongly increased PFS $(p<0.0001$; Figure 4A) and OS $(p<0.0001$; Figure 4B) were observed for $X A F 1$-M patients. While the observed median PFS of all patients with an $X A F 1-\mathrm{UM}$ state was 4.4 months, the group with $X A F 1$ methylation positive tumors showed a significantly increased PFS of 41.0 months (see Table 2). Although Kaplan-Meier survival curves also showed a significantly increased
OS for $X A F 1 \mathrm{M}$, the exact median survival could not be calculated, as the survival curve did not drop below 50\% at the end of the observation period. Stratifying according to the tumor histology (AA, AO and AOA vs. GB), the survival differences observed were specific for grade III tumor entities $(p<0.0001$; Figure 4C/4D), as they did not differ significantly in grade IV tumors (GB) (PFS: $p=0.3478$; Figure 4E, OS: $p=0.1964$; Figure 4F). Thus, $X A F 1$ methylation status represents a prognostic marker for grade III gliomas, being positively linked to PFS $(r=0.562, p<0.01)$ and OS $(r=0.525, p<0.01)$. In line 
with this, the median PFS is longer in $X A F 1-\mathrm{M}$ patients with grade III tumors when compared to the $X A F 1$-UM group (43.0 vs. 6.6 months), whereas it is not prolonged in grade IV patients (4.1 vs. 5.0 months) (Table 2).

According to the new WHO classification published in 2016, WHO grade III AA, AO and AOA have to be further classified according to their IDH1 status [4]. In AA, $I D H 1$-wild-type (IDH1wt) is an uncommon event and most of these cases share genetic similarities with $I D H 1 \mathrm{wt}$ GB $[38,39]$. Therefore, the IDH1 status was determined by IHC using an anti-IDH1 R132H antibody (Dianova) and was additionally validated by pyrosequencing. As expected, strongly increased PFS and OS $(p<0.0001)$ were observed for IDH1mut patients (Supplementary Figure 2A). The data indicate that among the 26 grade III tumors, 17 tumors showed the R132H mutation by both, IHC and pyrosequencing. Eight tumors showed an IDHlwt status by both techniques. One tumor was diagnosed as IDHlwt by IHC but pyrosequencing revealed a rare heterozygous mutation leading to an arginine $\rightarrow$ glycine (R132G) substitution (Supplementary Figure 3). According to the 2016 WHO guidelines, these eight tumors were defined as a separate class (grade III, IDH1wt). As a result, all grade III, IDH1mut tumors also showed methylation of XAF1 (Table 1).

In GB, only two out of eight $X A F 1-\mathrm{M}$ tumors were IDH1mut. In addition, these two have been histologically characterized as secondary GB, derived from AO.
The IDH1 and IDH2 status of the six GB samples was verified by pyrosequencing. Within these IDHwt GB, $X A F 1 \mathrm{M}$ tumors may form a distinct group. Due to the low number of these tumors in our cohort $(N=6)$, no difference, however, was observed for PFS and OS for $X A F 1$ methylation (Supplementary Figure 2B).

The high association between IDHI and XAFI status was also observed in recurrent gliomas (Table 3, Supplementary Table 2). Among 16 recurrent gliomas, all six recurrences derived from astrocytomas are $I D H 1$ mut/ $X A F 1-\mathrm{M}$. From the ten recurrent GB, eight are $I D H 1 \mathrm{wt} /$ $X A F 1-\mathrm{UM}$ and two are $I D H 1 \mathrm{mut} X A F 1-\mathrm{M}$, which points to their origin from a lower grade tumor. Indeed, these IDH1mut/XAF1-M tumors have derived from AA.

\section{DISCUSSION}

HGG are the most common and aggressive type of primary brain tumors. In our previous studies, we showed that cytotoxicity of the topoisomerase I inhibitor topotecan is strongly affected by the IAPs Survivin and XIAP [17] protecting GB cells from induction of apoptosis. A factor that counteracts these IAPs is the tumor suppressor XAF1. In vitro studies showed that XAF1 suppresses tumor cell growth and enhances the cellular response to various apoptotic stimuli [30]. Here we show that XAF1 has an impact on TMZ-induced apoptosis, as XAF1 knockdown in the GB cell line LN229 resulted in a decline of
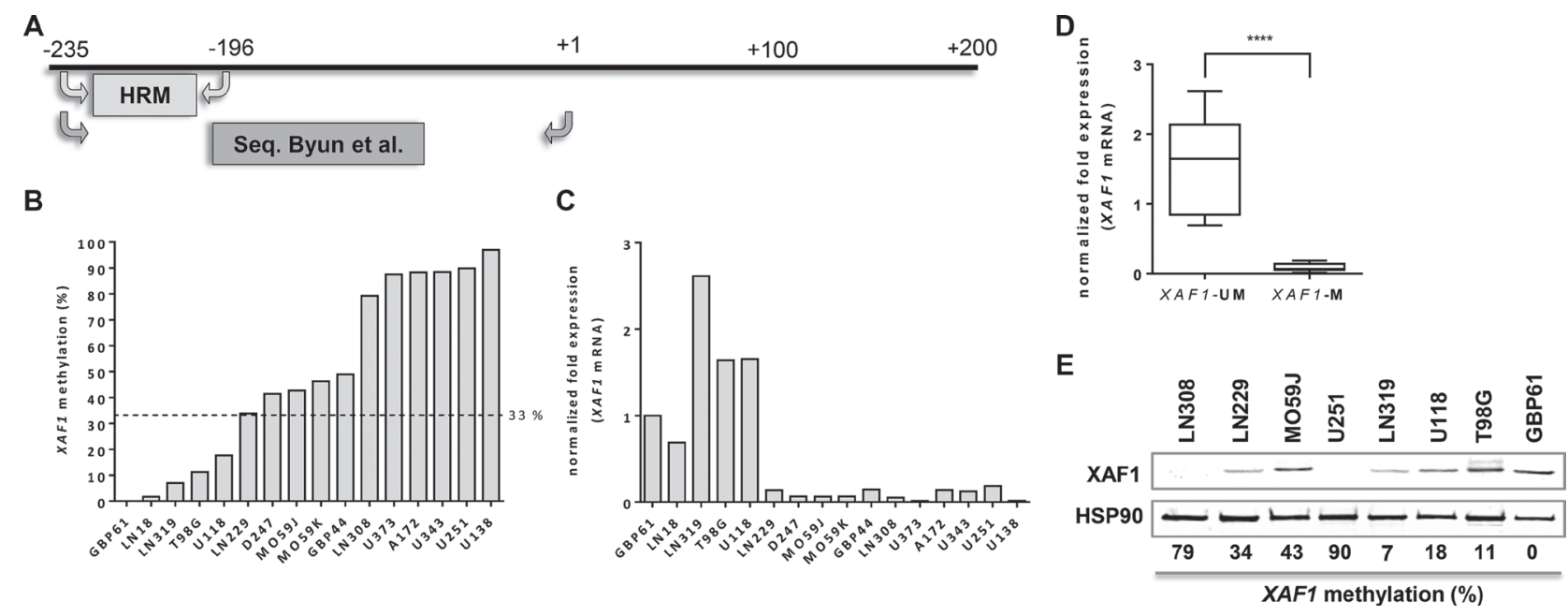

Figure 3: XAF1 methylation in glioma cell lines. (A) Schematic promoter region of $X A F 1$ with the location of MS-HRM primers used for this analysis and sequencing primers used by Byun et al. [46] (B) XAF1 promoter methylation in 16 GB cell lines analyzed by MS-HRM. The cell lines were ordered by the percentage methylation of the analyzed XAF1 promoter fragment starting with the lowest methylation value (from left to right). MS-HRM was carried out in technical duplicates of bisulfate-converted DNA of each cell line. The dotted line indicates the threshold of methylation which was applied for grouping. Samples with methylation values above 33\% were considered as "methylated". (C) XAF1 mRNA expression in 16 GB cell lines as determined by quantitative RT-PCR. The expression (relative to GBP61) of XAF1 mRNA is shown, normalized to $A C T B$ and ENOX2. Expression in each cell line was detected in technical triplicates (D) The grouping of the $16 \mathrm{~GB}$ cell lines according to XAF1 methylation status. Cell lines with a methylation value above $33 \%$ were considered to be methylated (M), whereas those with a methylation level of $\leq 33 \%$ were set as unmethylated (UM). Statistical significance for the difference in both groups was tested by a two-tailed $t$-test ( $p$-value $<0.0001,(* * * *))$. (E) XAF1 protein expression in selected GB cell lines with HSP90 loading control. The XAF1 promoter methylation percentages as determined by MS-HRM are indicated below the blot. 
apoptotic frequency. In TMZ-exposed XAF1 knockdown cells we observed a switch in the cell population from the G2- to the G1-phase, which suggested that these cells accumulate in G1 where they presumably get arrested for a while. In this case the G1-arrested cells will not form colonies, which could explain the missing difference in the colony formation of $X A F 1$ knockdown cells. As already mentioned, this could indicate that for long-term survival differences (as in glioma patients under TMZ therapy), the impact of XAF1 on cell cycle progression might play a predominant role.

XAF1 was previously shown to induce apoptosis independent of XIAP inhibition. Thus, XAF1 enhances p53 expression by antagonizing inhibition of p53 by MDM2 and increases HIPK2-dependent phosphorylation of p53 at Ser46 [40]. Phosphorylation of p53 at Ser46 leads to the transcription of pro-apoptotic genes and the execution of apoptosis [41]. In contrast, Ser15 phosphorylation drives the expression of the cell cycle regulator p21 [42] which is involved in the regulation of the p53-induced growth suppression [43, 44]. Lee et al. demonstrated a XAF1-induced down-regulation of p21 via stabilization of the p21-targeting E3 ubiquitin ligase ZNF313 [40] switching from cell cycle arrest to the induction of apoptosis. Furthermore, enhanced XAF1 expression was shown to inhibit cell proliferation and induce apoptosis, which was mainly associated with the induction of the G2/M arrest [33]. Cell cycle arrest in G2/M is explained by a direct interaction with CHK1 [34].

Taking the available data together, we suggest the following model. In TMZ- treated GB cells, XAF1 plays a role in the decision between apoptosis and cell cycle arrest. XAF1 down-regulation attenuates activation of CHK1 and therefore prevents from phosphorylation of p53 at Ser46, thereby abrogating the TMZ-induced G2arrest and apoptosis. By inducing the G1-arrest resulting from an elevated activation of $\mathrm{p} 21$, persistent reduced levels or absence of XAF1 could arrest the DNA synthesis, thereby preventing the replication- and mismatch repairdependent induction of DSB $[15,16]$, further reducing the apoptotic frequency (Figure 5). It is conceivable that this scenario has two outcomes: (i) the tumor cells either become irreversibly arrested in the G1/S-phase or (ii) they can progress at late times with newly formed DSB through S and G2 into mitosis, followed by induction of mitotic catastrophe. Both outcomes would result in tumor regression, leading to improved clinical outcome of XAF1-M tumors upon TMZ therapy. Since XAF1-M correlates with $I D H 1$ mutation, $X A F 1$ silencing could contribute to the enhanced survival of patients with $I D H 1$ mutations. Those cell cycle effects might be overshadowed by the overall G-CIMP in grade III IDHmut patients. Therefore, it is essential to analyze the impact of $X A F 1$ methylation in GB with $I D H 1$ wt status. The proposed model provides implications that need to be verified by further experiments.

As epigenetic silencing of $X A F 1$ occurs in different tumor entities [21, 24, 29, 45], we further addressed the question whether the $X A F 1$ promoter methylation is associated with clinical outcomes in HGG patients. A clinical impact of the XAF1 expression was already shown in epithelial ovarian cancer [22], pancreatic
A

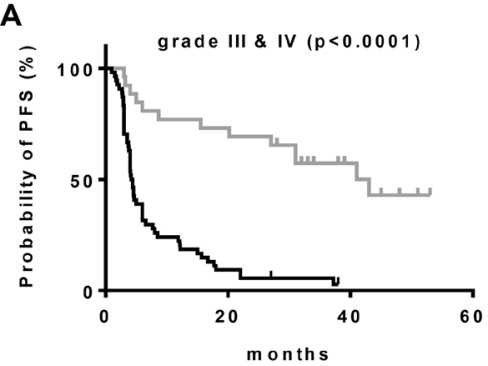

B

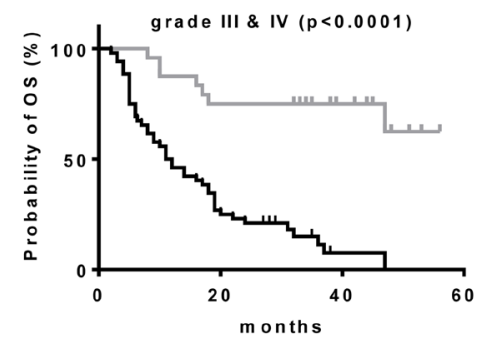

C

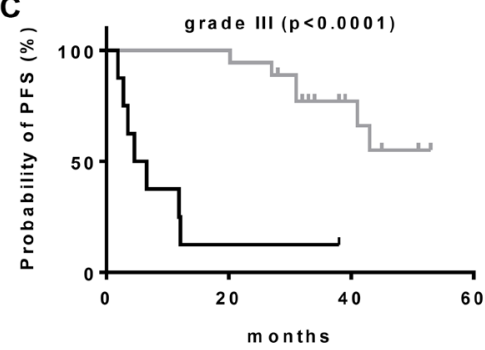

D

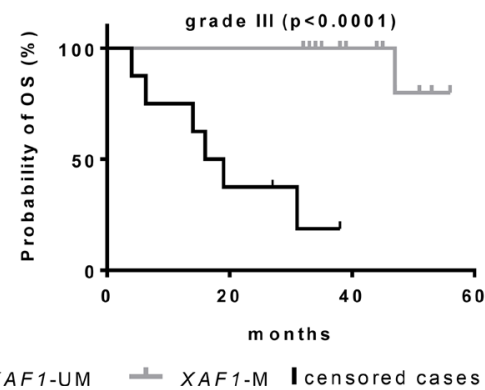

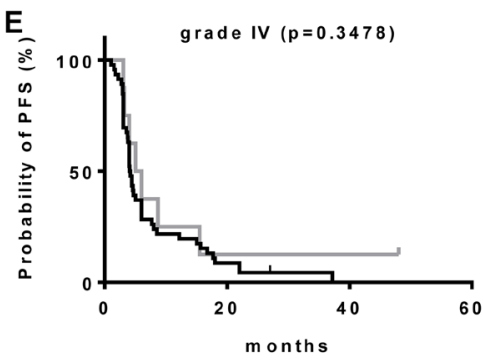

$\mathbf{F}$

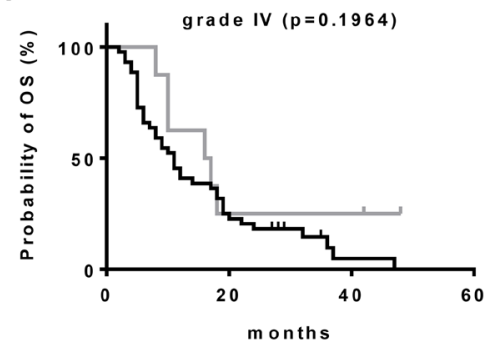

Figure 4: Kaplan-Meier survival estimates for HGG patients according to $X A F 1$ promoter methylation state. KaplanMeier survival estimates were calculated in a group of $80 \mathrm{HGG}$ patients stratified for methylated (M) and unmethylated (UM) XAFI promoter, determined by MS-HRM. Survival probability was calculated for all patients (grade III and grade IV) using the PFS (A) and OS (B) and for subgroups, further stratified for the histological tumor grade in grade III tumors (C, D) and in tumors of grade IV (E, F). $P$-values indicate the statistical significance of the differences in both groups (log-rank test). 
Table 3: $X A F 1$ promoter methylation status and $I D H 1$ status in $H G G$ patients

\begin{tabular}{|c|c|c|c|c|c|c|c|c|c|}
\hline & $\mathbf{N}$ & \multicolumn{3}{|c|}{$\begin{array}{c}X A F 1-\mathrm{M} \\
\%(\mathrm{~N})\end{array}$} & $\mathbf{N}$ & $\begin{array}{c}X A F 1-\mathrm{M} \\
\%(\mathrm{~N})\end{array}$ & & $\mathbf{N}$ & $\begin{array}{c}X A F 1-\mathrm{M} \\
\%(\mathrm{~N})\end{array}$ \\
\hline All & 80 & \multicolumn{2}{|c|}{$32.5(26)$} & Grade III & 26 & $69.2(18)$ & Grade IV & 54 & $14.8(8)$ \\
\hline$I D H 1 \mathrm{wt}$ & 60 & \multicolumn{2}{|c|}{$10.0(6)$} & $I D H 1 \mathrm{wt}$ & 8 & $0.0(0)$ & $I D H 1 \mathrm{wt}$ & 52 & $11.5(6)$ \\
\hline IDHImut & 20 & \multicolumn{2}{|c|}{$100.0(20)$} & IDHImut & 18 & $100.0(18)$ & IDH1mut & 2 & $100.0(2)$ \\
\hline $\operatorname{Cases}(N)$ & & $X A F 1-\mathrm{M}$ & \multicolumn{2}{|c|}{$X A F 1-\mathrm{UM}$} & IDH1mut & t IDH1wt & \multicolumn{2}{|c|}{$\begin{array}{l}\text { XAF1-M } \\
\text { IDH1mut }\end{array}$} & $\begin{array}{l}\text { XAF1-M } \\
\text { IDH1wt }\end{array}$ \\
\hline Grade III* (26) & & 18 & \multicolumn{2}{|c|}{8} & 18 & 8 & \multicolumn{2}{|c|}{18} & 0 \\
\hline Grade IV* (54) & & 8 & \multicolumn{2}{|c|}{46} & 52 & 2 & \multicolumn{2}{|l|}{2} & 6 \\
\hline $\begin{array}{l}\text { Grade III (18) } \\
I D H I \text { mut }\end{array}$ & & 18 & \multicolumn{2}{|c|}{0} & 18 & 0 & \multicolumn{2}{|l|}{18} & 0 \\
\hline $\begin{array}{l}\text { Grade III (8) } \\
\text { IDH1mut }\end{array}$ & & 0 & \multicolumn{2}{|c|}{8} & 0 & 0 & \multicolumn{2}{|l|}{0} & 8 \\
\hline $\begin{array}{l}\text { Grade IV (2) } \\
\text { IDHImut }\end{array}$ & & 2 & \multicolumn{2}{|c|}{0} & 2 & 0 & \multicolumn{2}{|l|}{2} & 0 \\
\hline $\begin{array}{l}\text { Grade IV (58) } \\
I D H I \text { mut }\end{array}$ & & 6 & \multicolumn{2}{|c|}{52} & 0 & 58 & \multicolumn{2}{|l|}{0} & 6 \\
\hline $\begin{array}{l}\text { Recurrent } \\
\text { grade III (6) }\end{array}$ & & 6 & \multicolumn{2}{|c|}{0} & 6 & 0 & \multicolumn{2}{|l|}{6} & 0 \\
\hline $\begin{array}{l}\text { Recurrent } \\
\text { Grade IV (10) }\end{array}$ & & $2^{+}$ & \multicolumn{2}{|c|}{8} & $2^{+}$ & 8 & \multicolumn{2}{|l|}{$2^{+}$} & 0 \\
\hline
\end{tabular}

*Histological tumor grading. ${ }^{+}$derived from OA.

tumors [23], clear-cell renal cell cancer [27], and gastric adenocarcinomas [46]. In all cases, a lower XAF1 expression was associated with poor prognosis. Due to the tumor-suppressing nature of XAF1, we anticipated a similar impact in HGG. Unexpectedly, methylation of the $X A F 1$ promoter was found to be significantly correlated

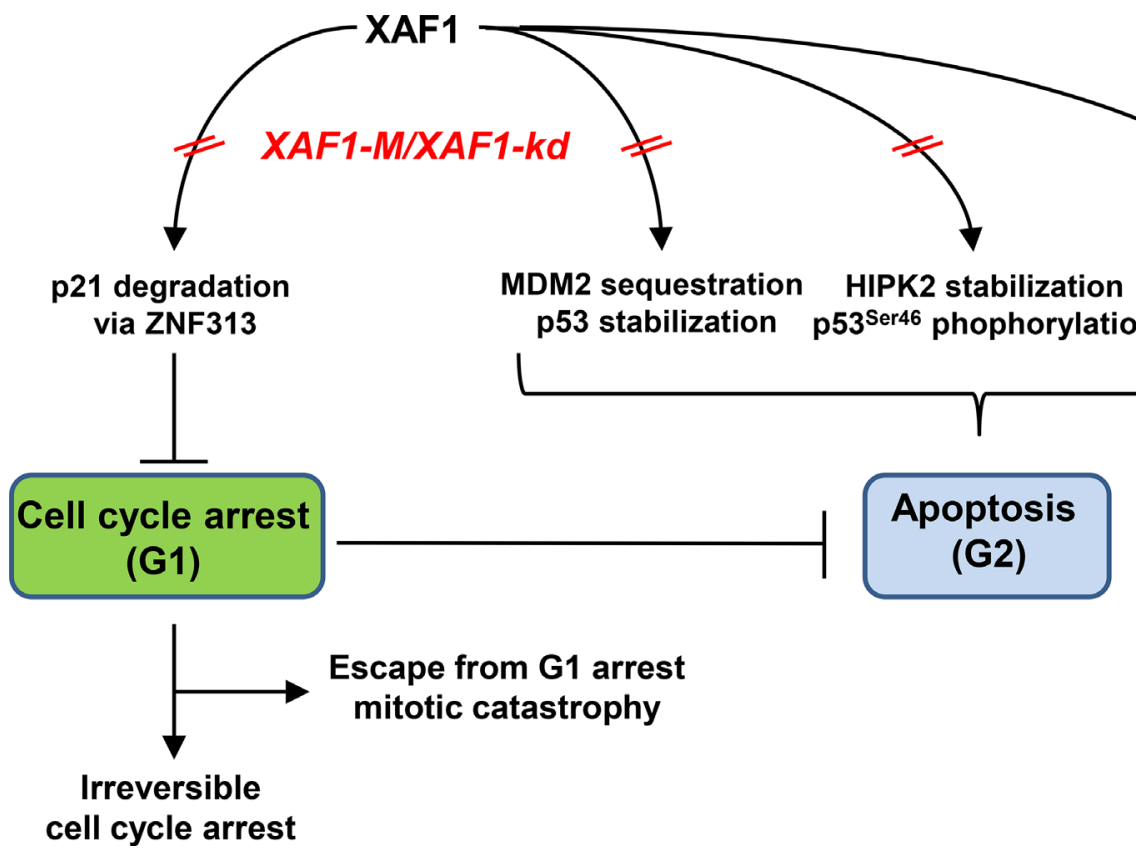

Figure 5: Potential impact of XAF1 on the decision between apoptosis and cell cycle progression upon TMZ treatment. 
with an improved OS and PFS in a collective of 80 HGG patients. To analyze the promoter methylation, we established a sensitive and quantitative high-throughput method (MS-HRM). Stratifying according to tumor histology revealed that the survival difference was specific for grade III gliomas (AA, AO and AOA) and suggested $X A F 1$ methylation to be a prognostic marker for these tumor entities. However, since diffuse gliomas represent a problem in the classification, different genetic markers have been tested, and the results have been integrated into the 2016 WHO classification guideline [4]. Thus, all diffuse gliomas have to be classified according to the $I D H$ status. In the case of AA, IDH1wt astrocytomas share a high genetic identity with GB [39, 45]. Therefore, it is highly important to separate these subtypes. For detection of $I D H 1$ mutations, the use of pyrosequencing in addition to conventional IHC detection is demanded for reliable classification. The most common (>95\%) IDH1 mutation leads to an R132H substitution [47], which causes a gain-of-function in the IDH1 enzyme. However, also other mutations at this position (R132C, R132S, R132G, $\mathrm{R} 132 \mathrm{~L}, \mathrm{R} 132 \mathrm{~V}, \mathrm{R} 132 \mathrm{P})$ have been reported [48].

Classifying the grade III tumors according to their IDH1 (R132H) status by IHC revealed that among these 26 tumors nine showed the IDH1wt status. On the contrary, 17 tumors carried a mutation in $I D H 1$ and were additionally methylated in $X A F 1$. Strikingly, among the IDH1wt tumors, only one tumor was found to be XAF1-M. Importantly, we identified this patient with an AA as a carrier of a rare IDH1 mutation (R132G), not detected by IHC. The false-negative $I D H 1$ status of this patient could be re-classified by pyrosequencing according to the $X A F 1$ methylation. Thus, we were able to show an absolute correlation (18 out of 18 ) between the $X A F 1$ methylation and the occurrence of 2-HG-producing IDH1 mutations, within grade III HGG (4 AO, 7 AOA, 7 AA). Vice versa, the eight IDH1wt grade III tumors had an unmethylated $X A F 1$ promoter. However, as discussed earlier, $I D H 1$ wt tumors with grade III histology show more similarities to the tumor entity of IDHIwt GB (grade IV) [4]. This has also been observed in the patients' survival. While the mean OS of patients harboring $I D H 1 \mathrm{wt} / X A F 1-\mathrm{UM}$ tumors was 16.4 months, patients with $I D H 1$ mut/XAF1-M AA/AOA had an OS of 54.2 months (Table 2). The low OS indicates that these IDH1wt/XAF1-UM tumors might actually represent grade IV GB. According to the 2016 WHO classification, this tumor group should be considered with caution, as it might resemble other tumor entities of higher grade.

In GB, only eight out of 54 tumors were $X A F 1-\mathrm{M}$. Two out of the eight $X A F 1$-M tumors were also IDH1mut. Interestingly, tumor histology indicated that these IDH1mut/XAF1-M tumors are secondary GB as they have been derived from OA of a lower grade. However, six XAF1-M GB did not show an IDH1 mutation at R132. To exclude a 2-HG-producing IDH2 mutation as well, we sequenced the corresponding position at R172 and could detect the $I D H 2$ wt sequence in all six samples (Supplementary Figure 6). By the exclusion of the most frequent 2-HG-producing mutations R132H, R132C, R132G, R132S, and R132L in IDH1 [48], and verification of the IDH2 R172 wt status [6] by pyrosequencing, we deduced that in GB, $X A F 1$ methylation can also occur independent of IDH1 R132 and IDH2 R172 mutations. However, since not all mutation spots in the $I D H 1$ and IDH2 genes producing 2-HG (e.g. IDH2 R140) have been determined and since $2-\mathrm{HG}$ production was not directly measured, it should be clarified whether $X A F 1$ methylation can also be caused by these rare mutations. Thus, $X A F 1$ methylation might provide an additional prognostic and/ or predictive value for this tumor entity. However, since the number of $I D H 1 \mathrm{wt} / X A F 1-\mathrm{M}$ tumors within the data set was very low, no conclusion concerning the impact of the $X A F 1$ status on the survival of these patients can be drawn yet.

The co-occurrence of IDH1 mutations and XAF1 methylation in grade III tumors (AA, AO, and AOA) indicates that the promoter methylation of $X A F 1$ might be a consequence of 2-HG produced in $I D H 1$ mutated cells. This hypothesis is supported by data from Turcan et al. [9] analyzing differentially methylated genes in IDH1-R132H expressing human astrocytes. Here, a 7.35-fold increased methylation in $\mathrm{CpGs}$ belonging to $X A F 1$ promoter can be found. Furthermore, comparing CIMP-positive vs. CIMP-negative tumors, a 2.63-fold repression of mRNA expression and a 3.23-fold enhanced methylation of $X A F 1$ was observed in the MSKCC cohort of lower grade glioma samples [9]. In a recent study on the methylation profile of the GB samples from the TCGA (The Cancer Genome Atlas) [38], a significant down-regulation of $X A F 1$ expression and hypermethylation was detected in G-CIMP proneural gliomas. Additional expression data of $X A F 1$ in G-CIMP-positive GB are, to our best knowledge, not available. Of note is that the G-CIMP phenotype is associated with IDH1 mutations in gliomas. The coincidence of $X A F 1$-M and $I D H 1$ mut in grade III gliomas explains why this subgroup shows a better survival despite opposite results (for the loss of XAF1) obtained in other tumor types. Therefore, $X A F 1$ methylation does not represent an independent prognostic marker in this particular tumor entity but provides a surrogate marker of $I D H 1$ and probably IDH2 mutations. The MS-HRMfacilitated detection of the $X A F 1$ methylation, presented in this study, thus could provide a fast and cheap diagnostic tool for assessing the $I D H$ status in tumor samples. Clinically, the IDH1 status is determined via pyrosequencing, which is more expensive and requires several working steps following DNA isolation. Different primer sets have to be established for $I D H 1$ and $I D H 2$ for each region of interest. Since about 95\% of $I D H 1$ mutations are R132H substitutions, IHC with IDH1R132H mutation-specific antibodies is most commonly used for 
diagnosis but might miss rare $I D H 1$ mutations and does not detect $I D H 2$ mutations. Also, discrepancies between IHC and DNA sequencing have been reported [49, 50]. Here, XAF1-targeted MS-HRM could provide a cheap and error-free high-throughput analysis for the detection of 2-HG-producing $I D H$ mutations. While we could provide evidence that $X A F 1$ methylation is strictly (100\%) linked to 2-HG-producing mutations in $I D H 1$ (shown for $\mathrm{R} 132 \mathrm{H}, \mathrm{R} 132 \mathrm{G}$ ) in grade III gliomas, we were not able to identify a less frequent $I D H 2$-mutant tumor within the data set. Thus, we can only speculate that 2-HG-producing IDH2 mutations might have the same impact on $X A F 1$ methylation. Before considering XAFl-targeted MSHRM as surrogate detection method for $I D H$ mutations in gliomas, this association would have to be proven in a larger cohort.

Considering XAF1 as tumor suppressor, the link between $X A F 1-\mathrm{M}$ and an improved OS/PFS might be attributed to the overall G-CIMP effects, which themselves are associated with a better prognosis. However, the exact nature of this phenotype is not understood in detail and does not provide a specific molecular explanation for the observed survival benefits. In either case, the initially anticipated disadvantageous effects of XAF1 silencing for the survival were disproved. The same was true for the influence of $X A F 1$ expression/XAF1 silencing on expression of its interaction partner XIAP. Since XIAP is post-translationally regulated by XAF1, a reduced XIAP level in XAF1-UM tumors could have been assumed. Thus we analyzed the protein level of XIAP in representative tumor samples (XAF1-M vs. XAF1-UM). IHC staining showed no differences in the levels of XIAP in either case (Supplementary Figure 5).

In summary, we could show that $X A F 1$ methylation can occur independently of IDH1 R132 and IDH2 R172 mutations. IDH2 R140 mutations characterized by a moderate $2-\mathrm{HG}$ production have not been analyzed here. As no significant difference in survival of this small group of patients with $I D H \mathrm{wt} / X A F 1-\mathrm{M}$ could be observed, when comparing with $I D H 1 w t / X A F 1-U M$ group, a negative influence of $X A F 1-\mathrm{M}$ on the survival cannot be excluded. Thus, an extended screening of primary GB with frequently occurring $I D H w$ genotype as to the promoter methylation state of $X A F 1$ is necessary to provide valuable information about $X A F 1$ methylation as an independent biomarker for this tumor entity.

\section{MATERIALS AND METHODS}

\section{Ethics statement}

Investigation has been conducted in accordance with the ethical standards and according to the Declaration of Helsinki and according to national and international guidelines and has been approved by the authors' institutional review board.

\section{Patients and treatment protocols}

DNA was isolated from formalin-fixed, paraffinembedded (FFPE) tumor samples from 80 patients with a first diagnosis of a high-grade glioma and from 16 patients with recurrent $\mathrm{HGG}$, treated at the Department of Neurosurgery of the University Medical Center, Mainz, Germany, between February 2011 and June 2013. Tumors had been assigned histologically to gliomas of WHO grade III and IV by a neuropathologist (C. Sommer). Tumor specimens were obtained by resection, performed before initiation of treatment (first diagnoses) and were immediately formalin-fixed and paraffin-embedded. Tumor material was micro-dissected for further analysis and tumor areas were labeled on the slides. In patients with GB and adequate postoperative clinical condition, a combined radio-chemotherapy with TMZ was performed according to the EORTC regimen $[14,51]$. In patients with $\mathrm{AA}^{\circ} \mathrm{III}$ or $\mathrm{AOA}^{\circ} \mathrm{III}$ a radio-chemotherapy according to NOA-04 protocol or alternatively a combined radiochemotherapy according to the EORTC regimen was performed [52]. In case of tumor progression, second-line therapy was administered, e.g. dose dense TMZ, CCNU or bevacizumab. All patients provided written informed consent. The study was approved by the institutional ethics committee of the University Medical Center Mainz.

\section{Cell culture}

Malignant glioma cell lines (U373, U138, LN308, U343, A172, U251, MO59J, MO59K, D247, LN229, LN18, GBP61, T98G, U118, LN319) were kindly provided by Prof. Weller (Laboratory of Molecular Neuro-Oncology, University Hospital and University of Zurich, Switzerland) and cultured in DMEM (Gibco) supplemented with 10\% fetal calf serum (Gibco) and grown at $37^{\circ} \mathrm{C}, 7 \% \mathrm{CO}_{2}$.

\section{Preparation of RNA and qRT-PCR}

Total RNA was isolated from cultured cells using the NucleoSpin ${ }^{\circledR}$ RNA extraction kit (Macherey-Nagel). The reverse transcription was performed with the Verso cDNA Synthesis Kit (Thermo Fisher Scientific) using random hexamer primers for cDNA synthesis. Real-time PCR was carried out with UltraMastermix (Promega) on a CFX96 Real-Time PCR Detection System (BioRad). The genes ENOX2 and $A C T B$ were used for normalization of the $X A F 1$ expression. ENOX2 and $A C T B$ primers were obtained from Primerdesign (UK) and expression was verified to be stable among different glioma cell lines with the best keeper software [53]. $X A F 1$ primers were specially designed for this analysis and were synthesized by Eurofins-Genomics (forward: 5'-AGCAGGTTGGGTGTACGATG-3' and reverse: 5'-CCTGGCACTCATTGGCCTTA-3'). 


\section{Preparation of protein extracts and western blot analysis}

Whole cell extracts were prepared as described [17]. For protein detection primary antibodies were diluted 1:1000 (XAF1: Pro-Sci 3207 \& Santa Cruz sc-374020, Survivin: R\&D Systems \#AF886, XIAP: Becton Dickinson BD \#610716, pCHK1/CHK1: Cell Signaling Technology CST \#2341 / CST \#2360, HSP90: Santa Cruz sc-13119). Appropriate secondary antibodies (1:2000; Rockland) were used for ECL detection (Pierce) or detection on the Odyssey infrared imaging system (1:10000; IRDye 680LT donkey anti-mouse IgG; Licor/ 1:10000; IRDye $800 \mathrm{CW}$ anti-rabbit IgG).

\section{Knockdown of XAF1}

$1 \times 10^{5}$ cells were seeded per $35-\mathrm{mm}$ dish. After $24 \mathrm{~h}$, knockdown of XAF1 was performed, using siRNA against $X A F 1$ with a final concentration of $10 \mu \mathrm{M}$ (Santa Cruz sc-37511) and Lipofectamine RNAiMAX Transfection Kit (Invitrogen).

\section{Determination of apoptosis, cell cycle distribution and metabolic competence}

For analysis of the sub-G1 (apoptosis), G1, S and G2 fractions cells were harvested and fixed at the indicated time points after TMZ treatment as described and were then analyzed by flow cytometry $[17,54]$. For unbiased analysis of the cell cycle distribution ModFit LT 3.3 Software was used for the calculations (Verity Software). In addition, induction of apoptosis and necrosis was determined by annexin V-FITC and propidium iodide (PI) double staining as described [17]. Cell viability, i.e. metabolic competence, was determined as described earlier [55]. $0.5 \mathrm{mg} / \mathrm{ml} \mathrm{3-(4,5-dimethylthiazol-2-yl)-2,5-}$ diphenyltetrazolium bromide (MTT) was added to the cells and the cells were incubated for $3 \mathrm{~h}$ under normal cell culture conditions. To solubilize the generated formazan crystals, the culture medium was removed and $100 \mu \mathrm{l}$ DMSO with $0.04 \mathrm{M} \mathrm{HCl}$ was added. The absorbance was measured at $570 \mathrm{~nm}$. Metabolic competence was calculated as percentage relative to the untreated control.

\section{Immunofluorescence staining of FFPE tumor sections}

Before staining FFPE tumor sections, specimens were deparaffinized. Sections, mounted on a microscopic slide, were pre-heated at $60^{\circ} \mathrm{C}$ for $30 \mathrm{~min}$ and afterwards incubated first in xylene $(3 \times 5 \mathrm{~min})$ and then in ethanol series (100/100/96/90/80/70\%). Rehydration was carried out by rinsing the sections $2 \times$ in $\mathrm{H}_{2} \mathrm{O}$ plus $1 \times$ in PBS.
Specimens were incubated in pre-heated citrate buffer (Target Retrieval Solution, Dako GmbH, Hamburg) in a steamer for $20 \mathrm{~min}$. For additional $20 \mathrm{~min}$, the samples were allowed to cool down at RT. After rinsing $2 \times$ in PBS, the sections were subjected to immunofluorescent staining. After blocking for $3 \mathrm{~h}$ with blocking solution (Dako $\mathrm{GmbH}$ ) in a humidified chamber at RT, samples were incubated with XIAP Ab (1:50; BD \#610716) in $\mathrm{PBS} / 2 \% \mathrm{BSA} / 0.1 \%$ TritonX-100 overnight at $4^{\circ} \mathrm{C}$. Incubation with secondary A488-conjugated $\mathrm{Ab}$ (1:500; Invitrogen A-11017) in $\mathrm{PBS} / 2 \%$ BSA was performed for $2 \mathrm{~h}$ at RT. Samples were washed $(3 \times 10$ min with $\mathrm{PBS} / 0.1 \%$ Tween-20), rinsed $1 \mathrm{x}$ in PBS, stained with TOPRO-3 (1:100) for 30 min and preserved with Vectashield Antifade Mounting Medium (Vector Laboratories Inc.).

\section{Isolation of genomic DNA and bisulfite conversion}

DNA from cell lines and FFPE samples was isolated using a phenol-chloroform, isoamyl alcohol (25:25:1) protocol followed by ethanol precipitation as described earlier [56]. The extracted DNA was resolved in DNAsefree water and nucleic acid purity and concentration was determined on a spectrophotometer (NanoDrop 2000c; Thermo Fisher Scientific). Absorbance quotients $\mathrm{A}_{260 / 280}$ of $\sim 2.0$ and $\mathrm{A}_{260 / 230}$ ratios of 2.0-2.2 were generally accepted as pure and DNA was stored for further use at $-20^{\circ} \mathrm{C}$. To address differences in CpG DNA-methyation, $500 \mathrm{ng}$ DNA were subjected to bisulfite conversion, using the EZ DNA Methylation ${ }^{\mathrm{TM}} \mathrm{Kit}$ (Zymo Research) according to the manufacturer's protocol.

\section{Analysis of the XAF1 promoter methylation by MS-HRM analysis}

Methylation-sensitive (MS) high-resolution melt (HRM) analysis was performed as described [37]. $20 \mathrm{ng}$ bisulfite converted DNA were amplified in duplicates by qPCR using a CFX96 Real-Time PCR Detection System (Bio-Rad). Primers were designed to amplify a 86 bp fragment containing 3 CpGs from -236 to -196 upstream of the XAF1 transcription start site (forward 5'-GGTTGTTAGTTTTAGGGAGGTAGA-3'; reverse 5'-TAGTAGGGGTTGGTTATGTTGT-3'). Melting data were analyzed and normalized using the Precision Melt Analysis Software (Bio-Rad). For sample interpolation, DNA standards with defined overall methylation value (Supplementary Figure 4B) were analyzed in every assay. The area under the curve (AUC) of the normalized melt curves was used to calculate a linear regression model (Supplementary Figure 4C) for the methylation standards (Prism 6.0c for Mac). \% methylation was interpolated from the standard curve. 


\section{Analysis of the XAF1 promoter methylation by pyrosequencing}

Pyrosequencing was performed on a PyroMark Q96 ID (Qiagen). Bisulfite converted DNA of selected samples was amplified by PyroMark PCR Kit (Qiagen). $1 \mu \mathrm{g}$ DNA was used with $0.28 \mu \mathrm{mol} / \mathrm{L}$ forward and 5'-biotinylated reverse primer. The biotinylated antisense strand was extracted with sepharose beads and used as template for sequencing reaction with $0.42 \mathrm{pmol} / \mu \mathrm{L}$ sequencing primer.

\section{Survival analysis}

Kaplan-Meier estimates for the PFS and the OS were calculated upon stratification for the XAF1 methylation status. The survival differences in both groups were tested for statistical significance by log-rank test (Mantel-Cox test). All statistics were computed using SPSS 23 (IBM) and plotted with Prism (version 6.0c for Mac).

\section{Statistical analysis}

Non-parametric Spearman's rank-order correlation was used to calculate the correlation coefficient (r) for the comparison of IDH1 status and XAF1 methylation. This correlation was tested for significance with a two-tailed test. Pearson correlation coefficient (r) was computed for comparison of $X A F 1$ methylation values (\%) determined by pyrosequencing vs. MS-HRM (Supplementary Table 1) and for the correlation of XAF1 mRNA expression vs. gene methylation. This correlation was tested for significance with a two-tailed test (SPSS). SubG1, annexin $\mathrm{V}$, and survival (MTT) data were analyzed for statistically significant differences by two-tailed $t$-test, comparing target siRNA (XAF1-si) vs. control siRNA (con-si) (Prism $6.0 \mathrm{c}$ for Mac).

\section{ACKNOWLEDGMENTS}

We thank Ms. Birgit Rasenberger for excellent technical assistance.

\section{CONFLICTS OF INTEREST}

The authors state no conflicts of interest.

\section{FUNDING}

The work was supported by the grants of the German Cancer Aid (Deutsche Krebshilfe/Dr. Mildred Scheel Stiftung) and the Intramural Research Funding of the University of Mainz to MTT, and by the grant of the Wilhelm Sander Foundation to MC. TRR was supported by a PhD stipend of the Rheinland-Pfalz Foundation (Stipendenstiftung Rheinland-Pfalz), and OJS holds a stipend from the International $\mathrm{PhD}$ program on the "Dynamics of Gene Regulation, Epigenetics and DNA Damage Response" from the Institute of Molecular Biology GmbH (Mainz, Germany) funded by the Boehringer Ingelheim Foundation.

\section{REFERENCES}

1. Louis DN, Ohgaki H, Wiestler OD, Cavenee WK, Burger PC, Jouvet A, Scheithauer BW, Kleihues P. The 2007 WHO classification of tumours of the central nervous system. Acta Neuropathol. 2007; 114:97-109.

2. Wen PY, Kesari S. Malignant gliomas in adults. N Engl J Med. 2008; 359:492-507.

3. Hainfellner J, Louis DN, Perry A, Wesseling P. Letter in response to David N. Louis et al, International Society of Neuropathology-Haarlem Consensus Guidelines for Nervous System Tumor Classification and Grading, Brain Pathology, doi: 10.1111/bpa.12171. Brain Pathol. 2014; 24:671-672.

4. Louis DN, Perry A, Reifenberger G, von Deimling A, Figarella-Branger D, Cavenee WK, Ohgaki H, Wiestler OD, Kleihues P, Ellison DW. The 2016 World Health Organization Classification of Tumors of the Central Nervous System: a summary. Acta Neuropathol. 2016; 131:803-820.

5. Parsons DW, Jones S, Zhang X, Lin JC, Leary RJ, Angenendt P, Mankoo P, Carter H, Siu IM, Gallia GL, Olivi A, McLendon R, Rasheed BA, et al. An integrated genomic analysis of human glioblastoma multiforme. Science. 2008; 321:1807-1812.

6. Yan H, Parsons DW, Jin G, McLendon R, Rasheed BA, Yuan W, Kos I, Batinic-Haberle I, Jones S, Riggins GJ, Friedman H, Friedman A, Reardon D, et al. IDH1 and IDH2 mutations in gliomas. N Engl J Med. 2009; 360:765-773.

7. Balss J, Meyer J, Mueller W, Korshunov A, Hartmann C and von Deimling A. Analysis of the IDH1 codon 132 mutation in brain tumors. Acta Neuropathol. 2008; 116:597-602.

8. Ward PS, Patel J, Wise DR, Abdel-Wahab O, Bennett BD, Coller HA, Cross JR, Fantin VR, Hedvat CV, Perl AE, Rabinowitz JD, Carroll M, Su SM, et al. The common feature of leukemia-associated IDH1 and IDH2 mutations is a neomorphic enzyme activity converting alphaketoglutarate to 2-hydroxyglutarate. Cancer Cell. 2010; 17:225-234.

9. Turcan S, Rohle D, Goenka A, Walsh LA, Fang F, Yilmaz E, Campos C, Fabius AW, Lu C, Ward PS, Thompson CB, Kaufman A, Guryanova O, et al. IDH1 mutation is sufficient to establish the glioma hypermethylator phenotype. Nature. 2012; 483:479-483.

10. Noushmehr H, Weisenberger DJ, Diefes K, Phillips HS, Pujara K, Berman BP, Pan F, Pelloski CE, Sulman EP, Bhat KP, Verhaak RG, Hoadley KA, Hayes DN, et al. Identification of a $\mathrm{CpG}$ island methylator phenotype that defines a distinct subgroup of glioma. Cancer Cell. 2010; $17: 510-522$. 
11. Ward PS, Cross JR, Lu C, Weigert O, Abel-Wahab O, Levine RL, Weinstock DM, Sharp KA, Thompson CB. Identification of additional IDH mutations associated with oncometabolite R(-)-2-hydroxyglutarate production. Oncogene. 2012; 31:2491-2498.

12. Dang L, Jin S, Su SM. IDH mutations in glioma and acute myeloid leukemia. Trends Mol Med. 2010; 16:387-397.

13. Koh J, Cho H, Kim H, Kim SI, Yun S, Park CK, Lee SH, Choi SH, Park SH. IDH2 mutation in gliomas including novel mutation. Neuropathology. 2015; 35:236-244.

14. Stupp R, Hegi ME, Mason WP, van den Bent MJ, Taphoorn MJ, Janzer RC, Ludwin SK, Allgeier A, Fisher B, Belanger K, Hau P, Brandes AA, Gijtenbeek J, et al. Effects of radiotherapy with concomitant and adjuvant temozolomide versus radiotherapy alone on survival in glioblastoma in a randomised phase III study: 5-year analysis of the EORTC-NCIC trial. Lancet Oncol. 2009.

15. Kaina B, Christmann M, Naumann S, Roos WP. MGMT: key node in the battle against genotoxicity, carcinogenicity and apoptosis induced by alkylating agents. DNA Repair (Amst). 2007; 6:1079-1099.

16. Christmann M, Verbeek B, Roos WP, Kaina B. O(6)Methylguanine-DNA methyltransferase (MGMT) in normal tissues and tumors: Enzyme activity, promoter methylation and immunohistochemistry. Biochim Biophys Acta. 2011; 1816:179-190.

17. Tomicic MT, Christmann M, Kaina B. Topotecan triggers apoptosis in p53-deficient cells by forcing degradation of XIAP and survivin thereby activating caspase-3-mediated Bid cleavage. J Pharmacol Exp Ther. 2010; 332:316-325.

18. Liston P, Fong WG, Kelly NL, Toji S, Miyazaki T, Conte D, Tamai K, Craig CG, McBurney MW, Korneluk RG. Identification of XAF1 as an antagonist of XIAP antiCaspase activity. Nat Cell Biol. 2001; 3:128-133.

19. Arora V, Cheung HH, Plenchette S, Micali OC, Liston P, Korneluk RG. Degradation of survivin by the X-linked inhibitor of apoptosis (XIAP)-XAF1 complex. J Biol Chem. 2007; 282:26202-26209.

20. Plenchette S, Cheung HH, Fong WG, LaCasse EC, Korneluk RG. The role of XAF1 in cancer. Curr Opin Investig Drugs. 2007; 8:469-476.

21. Zou B, Chim CS, Zeng H, Leung SY, Yang Y, Tu SP, Lin MC, Wang J, He H, Jiang SH, Sun YW, Yu LF, Yuen ST, et al. Correlation between the single-site $\mathrm{CpG}$ methylation and expression silencing of the XAF1 gene in human gastric and colon cancers. Gastroenterology. 2006; 131:1835-1843.

22. Wang Y, Mao H, Hao Q, Wang Y, Yang Y, Shen L, Huang S, Liu P. Association of expression of XIAP-associated factor 1 (XAF1) with clinicopathologic factors, overall survival, microvessel density and cisplatin-resistance in ovarian cancer. Regul Pept. 2012; 178:36-42.

23. Huang J, Yao WY, Zhu Q, Tu SP, Yuan F, Wang HF, Zhang YP, Yuan YZ. XAF1 as a prognostic biomarker and therapeutic target in pancreatic cancer. Cancer Sci. 2010; 101:559-567.

24. Chen XY, He QY, Guo MZ. XAF1 is frequently methylated in human esophageal cancer. World J Gastroenterol. 2012; 18:2844-2849.

25. Sakemi R, Yano H, Ogasawara S, Akiba J, Nakashima O, Fukahori S, Sata M, Kojiro M. X-linked inhibitor of apoptosis (XIAP) and XIAP-associated factor-1 expressions and their relationship to apoptosis in human hepatocellular carcinoma and non-cancerous liver tissues. Oncol Rep. 2007; 18:65-70.

26. Ng KC, Campos EI, Martinka M, Li G. XAF1 expression is significantly reduced in human melanoma. J Invest Dermatol. 2004; 123:1127-1134.

27. Kempkensteffen C, Fritzsche FR, Johannsen M, Weikert S, Hinz S, Dietel M, Riener MO, Moch H, Jung K, Krause H, Miller K, Kristiansen G. Down-regulation of the proapoptotic XIAP associated factor-1 (XAF1) during progression of clear-cell renal cancer. BMC Cancer. 2009; 9:276.

28. Fang X, Liu Z, Fan Y, Zheng C, Nilson S, Egevad L, Ekman P, Xu D. Switch to full-length of XAF1 mRNA expression in prostate cancer cells by the DNA methylation inhibitor. Int J Cancer. 2006; 118:2485-2489.

29. Lee MG, Huh JS, Chung SK, Lee JH, Byun DS, Ryu BK, Kang MJ, Chae KS, Lee SJ, Lee CH, Kim JI, Chang SG, Chi SG. Promoter CpG hypermethylation and downregulation of XAF1 expression in human urogenital malignancies: implication for attenuated p53 response to apoptotic stresses. Oncogene. 2006; 25:5807-5822.

30. Chung SK, Lee MG, Ryu BK, Lee JH, Han J, Byun DS, Chae KS, Lee KY, Jang JY, Kim HJ, Chi SG. Frequent alteration of XAF1 in human colorectal cancers: implication for tumor cell resistance to apoptotic stresses. Gastroenterology. 2007; 132:2459-2477.

31. Zhu LM, Shi DM, Dai Q, Cheng XJ, Yao WY, Sun PH, Ding Y, Qiao MM, Wu YL, Jiang SH, Tu SP. Tumor suppressor XAF1 induces apoptosis, inhibits angiogenesis and inhibits tumor growth in hepatocellular carcinoma. Oncotarget. 2014; 5:5403-5415. doi: 10.18632/oncotarget.2114.

32. Tu SP, Sun YW, Cui JT, Zou B, Lin MC, Gu Q, Jiang SH, Kung HF, Korneluk RG, Wong BC. Tumor suppressor XIAP-Associated factor 1 (XAF1) cooperates with tumor necrosis factor-related apoptosis-inducing ligand to suppress colon cancer growth and trigger tumor regression. Cancer. 2010; 116:1252-1263.

33. Tu SP, Liston P, Cui JT, Lin MC, Jiang XH, Yang Y, Gu Q, Jiang SH, Lum CT, Kung HF, Korneluk RG, Wong BC. Restoration of XAF1 expression induces apoptosis and inhibits tumor growth in gastric cancer. Int J Cancer. 2009; 125:688-697.

34. Wang J, Gu Q, Li M, Zhang W, Yang M, Zou B, Chan S, Qiao L, Jiang B, Tu S, Ma J, Hung IF, Lan HY, et al. 
Identification of XAF1 as a novel cell cycle regulator through modulating $\mathrm{G}(2) / \mathrm{M}$ checkpoint and interaction with checkpoint kinase 1 in gastrointestinal cancer. Carcinogenesis. 2009; 30:1507-1516.

35. Kim KS, Heo JI, Choi KJ, Bae S. Enhancement of cellular radiation sensitivity through degradation of Chk1 by the XIAPXAF1 complex. Cancer Biol Ther. 2014; 15:1622-1634.

36. Wojdacz TK, Dobrovic A. Methylation-sensitive high resolution melting (MS-HRM): a new approach for sensitive and high-throughput assessment of methylation. Nucleic Acids Res. 2007; 35:e41.

37. Switzeny OJ, Christmann M, Renovanz M, Giese A, Sommer C, Kaina B. MGMT promoter methylation determined by HRM in comparison to MSP and pyrosequencing for predicting high-grade glioma response. Clin Epigenetics. 2016; 8:49.

38. Cancer Genome Atlas Research N, Brat DJ, Verhaak RG, Aldape KD, Yung WK, Salama SR, Cooper LA, Rheinbay E, Miller CR, Vitucci M, Morozova O, Robertson $\mathrm{AG}$, Noushmehr $\mathrm{H}$, et al. Comprehensive, Integrative Genomic Analysis of Diffuse Lower-Grade Gliomas. N Engl J Med. 2015; 372:2481-2498.

39. Reuss DE, Kratz A, Sahm F, Capper D, Schrimpf D, Koelsche C, Hovestadt V, Bewerunge-Hudler M, Jones DT, Schittenhelm J, Mittelbronn M, Rushing E, Simon M, et al. Adult IDH wild type astrocytomas biologically and clinically resolve into other tumor entities. Acta Neuropathol. 2015; 130:407-417.

40. Lee MG, Han J, Jeong SI, Her NG, Lee JH, Ha TK, Kang MJ, Ryu BK, Chi SG. XAF1 directs apoptotic switch of p53 signaling through activation of HIPK2 and ZNF313. Proc Natl Acad Sci USA. 2014; 111:15532-15537.

41. Pietsch EC, Sykes SM, McMahon SB, Murphy ME. The p53 family and programmed cell death. Oncogene. 2008; 27:6507-6521.

42. Loughery J, Cox M, Smith LM, Meek DW. Critical role for p53-serine 15 phosphorylation in stimulating transactivation at p53-responsive promoters. Nucleic Acids Res. 2014; 42:7666-7680.

43. Li Y, Jenkins CW, Nichols MA, Xiong Y. Cell cycle expression and $\mathrm{p} 53$ regulation of the cyclin-dependent kinase inhibitor p21. Oncogene. 1994; 9:2261-2268.

44. el-Deiry WS, Tokino T, Velculescu VE, Levy DB, Parsons R, Trent JM, Lin D, Mercer WE, Kinzler KW, Vogelstein B. WAF1, a potential mediator of p53 tumor suppression. Cell. 1993; 75:817-825.

45. Hervouet E, Vallette FM, Cartron PF. Impact of the DNA methyltransferases expression on the methylation status of apoptosis-associated genes in glioblastoma multiforme. Cell Death Dis. 2010; 1:e8.

46. Byun DS, Cho K, Ryu BK, Lee MG, Kang MJ, Kim HR, Chi SG. Hypermethylation of XIAP-associated factor 1, a putative tumor suppressor gene from the $17 \mathrm{p} 13.2$ locus, in human gastric adenocarcinomas. Cancer Res. 2003; 63:7068-7075
47. Zhao S, Lin $Y, X u$ W, Jiang W, Zha Z, Wang P, Yu W, Li Z, Gong L, Peng Y, Ding J, Lei Q, Guan KL, et al. Gliomaderived mutations in IDH1 dominantly inhibit IDH1 catalytic activity and induce HIF-1alpha. Science. 2009; 324:261-265.

48. Pusch S, Schweizer L, Beck AC, Lehmler JM, Weissert S, Balss J, Miller AK and von Deimling A. D-2-Hydroxyglutarate producing neo-enzymatic activity inversely correlates with frequency of the type of isocitrate dehydrogenase 1 mutations found in glioma. Acta Neuropathol Commun. 2014; 2:19.

49. Agarwal S, Sharma MC, Jha P, Pathak P, Suri V, Sarkar C, Chosdol K, Suri A, Kale SS, Mahapatra AK, Jha P. Comparative study of IDH1 mutations in gliomas by immunohistochemistry and DNA sequencing. Neuro Oncol. 2013; 15:718-726.

50. Li J, Zhang H, Wang L, Yang C, Lai H, Zhang W, Chen X, Wang J. Comparative study of IDH1 mutations in gliomas by high resolution melting analysis, immunohistochemistry and direct DNA sequencing. Mol Med Rep. 2015; 12:4376-4381.

51. Stupp R, Mason WP, van den Bent MJ, Weller M, Fisher B, Taphoorn MJ, Belanger K, Brandes AA, Marosi C, Bogdahn U, Curschmann J, Janzer RC, Ludwin SK, et al. Radiotherapy plus concomitant and adjuvant temozolomide for glioblastoma. N Engl J Med. 2005; 352:987-996.

52. Wick W, Hartmann C, Engel C, Stoffels M, Felsberg J, Stockhammer F, Sabel MC, Koeppen S, Ketter R, Meyermann R, Rapp M, Meisner C, Kortmann RD, et al. NOA-04 randomized phase III trial of sequential radiochemotherapy of anaplastic glioma with procarbazine, lomustine, and vincristine or temozolomide. J Clin Oncol. 2009; 27:5874-5880.

53. Pfaffl MW, Tichopad A, Prgomet C, Neuvians TP. Determination of stable housekeeping genes, differentially regulated target genes and sample integrity: BestKeeperExcel-based tool using pair-wise correlations. Biotechnol Lett. 2004; 26:509-515.

54. Tomicic MT, Friedrichs C, Christmann M, Wutzler P, Thust R, Kaina B. Apoptosis induced by (E)-5-(2bromovinyl)-2'-deoxyuridine in varicella zoster virus thymidine kinase-expressing cells is driven by activation of c-Jun/activator protein-1 and Fas ligand/caspase-8. Mol Pharmacol. 2003; 63:439-449.

55. Tomicic MT, Aasland D, Naumann SC, Meise R, Barckhausen C, Kaina B, Christmann M. Translesion polymerase eta is upregulated by cancer therapeutics and confers anticancer drug resistance. Cancer Res. 2014; 74:5585-5596.

56. Christmann M, Nagel G, Horn S, Krahn U, Wiewrodt D, Sommer C, Kaina B. MGMT activity, promoter methylation and immunohistochemistry of pretreatment and recurrent malignant gliomas: a comparative study on astrocytoma and glioblastoma. Int J Cancer. 2010; 127:2106-2118. 